\title{
JÁ VISTO JAMAIS VISTO: UM FILME DE FILMES OU O DEVIR MEMÓRIA
}

\section{Roberta Veiga*}

\begin{abstract}
Resumo: Esse ensaio busca refletir sobre o modo como a escrita de si de Andrea Tonacci no filme Já visto jamais visto (2013) retira sua potência do trabalho de invenção da memória. A ideia é de que Tonacci é menos personagem de uma narrativa pessoal do que o próprio cineasta que, ao colocar seu gesto em perspectiva, e (re)ver quarenta anos de trabalho, lembranças guardadas e esquecidas em milhares de rolos de filmes, habita um espaço entre-imagens e sujeitos, no qual o cinema opera relações temporais e reencontra uma dimensão porosa e lacunar, onírica e mnemônica. É justamente porque a memória se constitui mesmo no processo de feitura do filme, e não como algo fora que precisa se resgatar ou se conservar como um patrimônio subjetivo, que ela não se coloca como um dever biográfico e histórico, mas como um devir, um devir cinema.
\end{abstract}

Palavras-chave: Tonacci. Escrita de si. Memória. Já visto jamais visto.

Se o projeto de Olho por olho (1965), filme de estreia de Tonacci, nasce das conspirações juvenis e, Blá blá blá (1968), da ânsia contida nos primeiros passos políticos de um jovem, Já visto jamais visto (2013) parece ter origem na angústia de um homem vivido frente a experiência da memória. Nesse cinema-ensaio, Tonacci vai olhar para quarenta anos de trabalho, lembranças guardadas e esquecidas em milhares de rolos de filmes.

"O tecido do tempo é fundamentalmente lacunar e a continuidade temporal não deve ser entendida como um dado, mas como uma obra, uma construção do sujeito, diante sobretudo da angústia que significa para ele, o ato de reviver o desaparecido (e, por tanto, o descontínuo), de enfrentar a morte" afirma Lucia Castello Branco (1990, p. 41), na esteira de Gaston Bachelard. Para Bachelard, o tempo não é uma dimensão exterior ao sujeito, mas o resultado da maneira como ele aí se inscreve. Ao se voltar para o passado, o continuum é um desejo do sujeito de organizar "a desordem e o caos que a vida o submete" (CASTELLO BRANCO, 1990, p. 42). Tonacci parte desse desejo que é também um desejo de cinema: o caos está lá nos filmes, em diversos formatos, nos pedaços de histórias e ficções, nas fotografias e arquivos de família, que, mesmo catalogados, dispõem o tempo nessa dimensão descontínua, onde qualquer tentativa de linearidade enfrenta saltos e buracos, e se dispersa tal qual a memória.

Como testemunha Patrícia Mourão (2012, p. 98), produtora do filme, durante a elaboração do projeto, era difícil para Tonacci cotejar suas lembranças com as imagens que teria feito. Dupla angústia, aquela própria à escrita de si que ao debruçar-se sobre o passado encontra o esquecimento e a do cineasta cujo esquecimento não pode ser sanado pela imagem preservada do passado. Dupla impossibilidade do gênero autobiográfico e sua lógica ilusória: a primeira, a pretensão dos textos confessionais de uma permanência narrativa daquilo que já não é; e a segunda, própria ao cinema do eu,

\footnotetext{
* Doutora em Comunicação Social pela Universidade Federal de Minas Gerais (UFMG). Professora adjunta da UFMG. E-mail: roveigadevolta@gmail.com.
} 
depositar no registro, no arquivo-imagem, a possibilidade de preservação da memória em sua continuidade. Mas é justamente nessa impossibilidade da memória que reside a grande potência das formas de escritas de si. É no caminho de busca pelo que já foi que se edifica o que ainda não é, ou seja, ao voltar-se para o passado e encontrar lacunas e vazio, é no presente que o sujeito constrói um vir a ser, alguma coisa que se coloca entre o passado e o esquecimento dele: a obra, ela mesma, como memória. Eis o trabalho do filme de Tonacci, que ao contrário de um dever biográfico e histórico cuja pretensão seja reescrever o passado cronologicamente, se funda na memória enquanto obra, processo, construção, atravessada que é pelo esquecimento, portanto um tecido poroso e esgarçado, que através da montagem ganha materialidade expressiva.

Por abrir mão de uma função memorialista redutora calcada na postura nostálgica, por não tentar preencher o passado de uma vida pessoal ou do cinema brasileiro, mas por acontecer nessa impossibilidade de volta no tempo que lhe é constituinte, Já visto jamais visto se distancia do dever de memória e se lança a um devir memória, um tornar-se memória. O dever de memória é esse que, segundo François Hartog (2013, p. 14-15), faz da história o registro, a preservação de um passado que precisa se manter intacto para não se perder frente ao presentismo contemporâneo, um presente onipresente que, em seu imediatismo, ao mesmo tempo em que nada conserva, nada quer esquecer. Também Pierre Nora, ao refletir sobre a separação entre história e memória, diz:

\begin{abstract}
A necessidade da memória é uma necessidade da história.[...] Aceitamos isso, mas com a consciência clara da diferença entre memória verdadeira, hoje abrigada pelo gesto e no hábito, nos ofícios onde se transmitem os saberes do silêncio, nos saberes do corpo, as memórias de impregnação e os saberes reflexos e a memória transformada por sua passagem em história, que é quase o contrário: voluntária e deliberada, vivida como um dever e não mais espontânea... (NORA, 1981, p. 14).
\end{abstract}

Em detrimento da aposta numa volta ao passado, seja através de (re)encenações de acontecimentos, (re)visitações a lugares do passado, ou do uso excessivo de arquivos domésticos, como é comum em obras autobiográficas - que traçam uma continuidade temporal ao narrativizar um tema familiar - Já visto jamais visto sugere uma relação com o passado marcada pela distância, pelo não pertencimento, justamente em função da indiscernibilidade entre o eu, o cineasta e o cinema. Ao internalizar a descontinuidade entre passado e presente em sua forma, numa montagem que justapõe materiais heterogêneos, esse cinema expõe a própria história, como parece desejar Nora': uma operação (de pôr em relação). Tonacci é menos personagem de uma narrativa pessoal do que o próprio cineasta que ao colocar seu gesto em perspectiva ao (re)ver seus filmes produz memória.

É justamente porque a memória se constitui mesmo no processo de feitura do filme, e não como algo fora que precisa se resgatar ou se conservar como um patrimônio

\footnotetext{
1 “Sem dúvida, para que haja um sentimento de passado, é necessário que ocorra uma brecha entre o presente o passado, que apareça um "antes" e um "depois". Mas trata-se menos de uma separação vivida no campo da diferença radical do que um intervalo vivido no modo de filiação restabelecida."(NORA, 1984, p. 19) Caberia ao cinema essa operação de, ao montar, colocar em relação passado e presente.
} 
subjetivo, que ela não se coloca como um dever, mas como um devir, que na verdade é também um devir cinema. Ao contrário do que diria Nora, sobre um certo uso documental abusivo do arquivo que obedece ao dever de memória ${ }^{2}$, o cinema que aqui recorre ao arquivo é menos como um suporte material, lugar de fixação do passado, do que um espaço onde a história pode se dar como operação que sobrevive ruidosa, rugosa, e porosa, pois o próprio ato cinematográfico, a montagem principalmente, é que vai habitar a memória ${ }^{3}$ aproximando presente e passado. A memória não é um dever, mas um devir, um devir cinema, e habitar o lugar do cinema é habitar o lugar da memória.

É como se Tonacci, ao se colocar em obra, no gesto que funda uma escrita de si, estivesse sempre a um passo de se tornar memória para se tornar cinema ou vice-versa. Já visto jamais visto é um filme feito de filmes, feitos e inacabados, ficcionais, documentais e caseiros, daí sua dimensão ensaística híbrida e aberta. Esses filmes, como suporia Mondzain, não são primeiramente imagens de pessoas ou coisas, mas aparições prontas a desaparecerem em qualquer momento. É nesse registro que as imagens operam entre elas e entre sujeitos. "Godard repetiu e escreveu mais do que uma vez que a imagem está entre os sujeitos, e que, reciprocamente, o sentido da imagem está entre as imagens" (MONDZAIN, 2011, p. 109). A hipótese é de que a natureza dos rastros de um tempo, sempre fugidio, e a conjugação deles fazem da força criativa do filme de Tonacci um entre (imagens e sujeitos), e por isso um fora, um devir outro.

É justamente por se opor a esse dever que o devir memória em Tonacci só existe na dimensão processual do filme e sobrevive através da montagem aberta que o sustenta. Por mais que vejamos esse filme, jamais o veremos inteiro, há sempre conexões a serem feitas e faltas a serem descobertas, sem que haja um sentido único a ser revelado, ele será ao mesmo tempo já visto e jamais visto, de forma que o tornar-se outro nunca se esgote. Daí a espera de um terceiro, o espectador que ainda virá, como constituinte do filme em sua dialética insolúvel. "O terceiro não ocupa o lugar do todo porque a imagem é um regime de deslocação, no sentido próprio da palavra. A imagem não tem lugar. Utopia e distopia, ela instaura a temporalidade histórica de uma circulação de lugares." (MODZAIN, 2011, p. 109).

Pensamos Já visto jamais visto em três partes difusas e sobrepostas - que aqui denominamos: o filho, o cineasta, e o pai - além de um epílogo metalinguístico no qual acompanhamos Tonacci ler uma passagem de Alberto Moravia, do livro O Desprezo, a respeito da distância entre um roteiro, com seus argumentos, e o trabalho próprio do filme. A primeira parte, $O$ filho, tem como base o filme inacabado, Paixões, de 1994,

\footnotetext{
${ }^{2} \mathrm{O}$ dever de memória nesse contexto de obsessão pelo arquivo, para Nora, pode ser definido nessa asserção: "O sentimento de um desaparecimento rápido e definitivo combina-se à preocupação com o exato significado do presente e com a incerteza do futuro para dar ao mais modesto dos vestígios, ao mais humilde testemunho a dignidade virtual do memorável." (1984, p. 14).

3 "Se habitássemos ainda nossa memória, não teríamos necessidade de lhe consagrar lugares. Não haveria lugares porque não haveria memória transportada pela história. Cada gesto, até o mais cotidiano, seria vivido como uma repetição religiosa daquilo que sempre se fez, numa identificação carnal do ato e do sentido. Desde que haja rastro, distância, mediação, não estamos mais dentro da verdadeira memória, mas dentro da história. [...] A história é a reconstrução sempre problemática e incompleta do que não existe mais. A memória é um fenômeno sempre atual, um elo vivido no eterno presente; a história, uma representação do passado". (NORA, 1984, p. 19).
} 
que, na verdade, se apresenta como o dispositivo disparador da obra, sem que seja seu epicentro, como o cineasta mesmo admite (TONACCI, 2012, p. 138). Análogo a uma teia mnemônica, Já visto jamais visto não tem núcleo, mas passagens, deslocamento, e essas partes deslizam umas sobre as outras, ora se atraindo ora se afastando.

\section{O FILHO}

Na casa de campo de Tonacci, em Extrema (entre Minas e SP), entre serras e sons de sapos, um filme está sendo feito. Após a claquete, o menino, o filho, se prepara para dormir. O palhaço da velha caixinha de música dança desengonçado, e então somos lançados ao que parece ser o sonho do menino. Escondido atrás de uma pedra, no meio do mato, com seu boné vermelho, o menino vê um objeto rolar junto com a terra que o trator arrasta. Ele corre, consegue pegá-lo e foge com a certeza de que achou algo precioso, talvez um tesouro, desses que os meninos das historias de aventuras, exploradores e piratas, desejam encontrar. É uma botija, que pode conter moedas, pedras preciosas, ou coisas mágicas. Mas alguém está em seu encalço, um homem de chapéu, óculos e uma lupa. Através dela, ele vê o menino que anda pelo mato carregando o valioso objeto até encontrar um lugar seguro, sua casa no alto de uma árvore.

A botija the parece familiar, com destreza ele tira tudo que há dentro e se depara com uma enorme chave que observa como quem reconhece o objeto esperado. Uma chave pesada de ferro, que parece ter vindo de um outro tempo, de um passado remoto, e tudo que ela pode abrir no universo infantil: armários ou baús velhos, grandes cofres, a porta de um casarão, ou até mesmo um passado, castelos, tesouros, outros mundos, livros de literatura infanto-juvenis... Refugiado em sua cabana selvagem (abrigo tão almejado pelas crianças), o menino esconde a chave num baú de madeira. O homem da lupa se aproxima, olha para cima e descobre o esconderijo, sobe desajeitadamente, e ao chegar ao topo, lá está o menino a lhe encarar com um rifle na mão. Os olhares se encontram - um corte, o som de um trovão e não saberemos mais nada desse encontro, inacabado ele jamais será visto.

A próxima imagem surge do escuro, um homem de cabelos longos (interpretado pelo ator Sérgio Mambert), que parece vindo do passado, olha pela janela. Uma cobra num vidro, formigas sobem numa folha verde, um inseto passeia num fino véu branco, tudo parece maior, parece visto pela lupa e tudo se confunde em sobreimpressões. O som de trovão, do inseto, do sino da casa que toca várias vezes e da chuva que cai com força se sucedem criando uma ambiência de suspense, um misto de passado e natureza, elementos incontroláveis e misteriosos.

O som que se segue também vem de um passado remoto, é o rufo de um gongo, instrumento chinês do século VI. Ele preenche uma sequencia de pinturas que se sobrepõe. Estamos dentro da casa, quando a sombra de um homem de gorro e uniforme militar surge em quadro, ele aconchega com a manta o menino que dorme. Esse homem é Andrea Tonacci, e o menino caçador de tesouros que agora se aquieta para aguardar o sono é seu filho, Daniel. A câmera fecha no rosto da criança, e é dali que sai mais uma 
vez como se o universo que estamos prestes a adentrar novamente emanasse do sono do menino, como uma imagem onírica. A câmera sobe até a janela, que agora nos levará não mais para as serras que circundam aquela casa de campo onde meninos caçadores, tesouros misteriosos e perseguições têm lugar, mas a um portal escuro que se abre para um pátio iluminado cercado por uma enorme construção antiga, de janelas e portas arredondas. É uma cidade italiana, Roma provavelmente. O menino caminha por ruas de pedras, em direção a um castelo, faz frio.

O mesmo caçador de objetos perdidos vai agora explorar o mundo antigo. Ele perambula entre lagos e pontes, torres e escadarias, até chegar a enorme porta de uma igreja, um plano de detalhe mostra uma imensa fechadura, o menino coloca o dedo, como se lembrasse da chave que guardara em sua casa da árvore. A fechadura parece exata pra ela, mas como acontece no sonho, na memória e na imagem, o objeto preciso já não está mais ali, é uma ausência. Parece haver, como diria Benjamin sobre Proust, "a semelhança entre dois seres, a que estamos habituados no estado da vigília é apenas um reflexo impreciso da semelhança mais profunda que reina no mundo dos sonhos, em que os acontecimentos não são nunca idênticos, mas impenetravelmente semelhantes entre si”. (BEMJAMIN, 1994, p. 39).

Do vidro de uma cabine telefônica, vemos a cidade. Enquanto o menino folheia uma revista, o pai diz, em italiano, "meu nome a Andrea Tonacci". A cena vem anunciar que o estado da imagem - que se assemelha ora a mais um sonho de menino, ora a uma lembrança de infância, ora a um filme de aventura, protagonizado pelo menino explorador de relíquias, filho do homem de uniforme militar - é um filme de família, um diário da viagem que Tonacci fez com Daniel a sua terra natal.

Já nessa primeira parte, no encontro entre um filme inacabado, Paixões, e um arquivo de família, Tonacci parece querer insistir em nos dizer que não há mesmo tanta diferença entre o cinema, o sonho de uma criança, a memória e todo um passado antigo, pois deles só temos vestígios (relíquias mágicas e misteriosas). Parece ainda nos mostrar que a matéria que os constituem não é feita só de imagens, registros de um momento vivido, já visto, mas de entre-imagens, instantes jamais vistos, porém experimentados no presente da montagem do filme e no futuro, a cada vez que o filme encontrar uma nova audiência. A montagem de Tonacci - a ligação, ou melhor, os saltos entre as imagens, os tempos, as narrativas - é tão lacunar quanto a experiência dos sonhos e da própria memória, onde personagens permutam lugares e tempo, nomes e aparências, são velhos e novos, pais que são também filhos, crianças também adultos, temporalidades transversais.

É porque a imagem não é nem uma coisa nem uma pessoa que ela opera entre sujeitos enquanto operadora de uma relação, sem usufruir, ela própria, de nenhum estatuto ontológico, nem teológico, e, sobretudo, sem se reduzir à sua materialidade (MONDZAIN, 2011, p.109).

No filme de Tonacci, o menino pode estar na Itália e ao mesmo tempo sobrevoando Nova York, pode andar nas pedras ou nas nuvens, pode estar no presente da viagem com o pai e no passado remoto de uma civilização inteira. Uma belíssima cena do filme parece metaforizar esse comportamento surreal comum tanto ao gesto cinematográfico, quanto à dimensão onírica e mnemônica, esse entre-lugar das imagens: 
nela se está no fundo do mar, ou dentro de um aquário, entre as águas que se movem com os peixes, e ao mesmo tempo em um bosque verde cheio de árvores, cercado de montanhas. Trata-se de uma sobreimpressão de imagens, uma condensação da mistura de cores, texturas, ambientes e temporalidades, presente em todo o filme. As folhas da árvore não balançam com o vento, mas com as águas, e o sol nasce dentro daquele enquadramento-aquário. Os peixes se vão e a árvore fica, e é dela que surge novamente, numa fusão, o pequeno caçador de relíquias que ainda dorme junto ao palhaço dançante.

Pouco depois que a criança acorda, assistimos a uma filmagem de bastidores de Paixões, feita durante um almoço na casa de campo em que Tonacci, o pai, se revela o diretor do filme e conversa com o homem da lupa, o ator Joel, personagem do investigador, enquanto o filho brinca por perto. Nesse momento, vão aparecer os elementos que compõem ou comporiam a história ficcional do filme inacabado, a cobra no pote de vidro, a chave, a botija, uma bíblia de 1884 e uma pequena escultura de Jesus crucificado, tudo que Tonacci exibe com admiração, como relíquias verdadeiras de uma ficção e ele também um caçador delas, ele que costumava examinar as pinturas, as fotos, objetos do passado com uma lupa.

\section{O CINEASTA}

Enquanto diz "é esse o Cristo", Tonacci sustenta a imagem no ar, que se dissolve na primeira das várias cenas de seus outros filmes, já vistas e jamais vistas, que agora estão, como ele mesmo diz, "de volta ao mundo" (TONACCI, 2012, p. 140). É o cinema brasileiro que vai surgir na tela, porém, longe de qualquer história que o catalogue, de qualquer cronologia, de um dever de memória que busque preservá-lo como patrimônio, mas num regime de historicidade próprio à vertigem do processo de feitura do filme, do gesto de montagem e das escolhas de Tonacci, uma temporalidade singular. Cada cena ali é também uma relíquia tal qual aqueles elementos que o diretor exibe como os elos fundamentais que constituirão sua ficção, objetos cheios de mistério, mas também precisos pra designar por si só todo um discurso, uma narrativa histórica, dentro da história do filme. Assim são as cenas dos filmes, elas apontam pra elas mesmas como um conjunto de elementos formais e diegéticos que compõe uma imagem e uma narrativa tanto histórica quanto fictícia, mas apontam pra fora delas para uma constelação de outras cenas e filmes que compõe o cinema de Tonacci, o cinema brasileiro, a história do cinema imiscuída à história do Brasil.

Dessa forma é que o devir memória se processa no devir cinema. A autobiografia de Tonacci, seu arquivo pessoal, se mistura com o próprio cinema brasileiro. As escavações não são as relíquias de um passado remoto, mas de um passado bem mais próximo, quando, no final dos anos 60, a rua era o lugar de encontro do jovem cineasta e seus amigos, onde, ao lado de Sganzela, ele conspirava em forma de filmes, quando juntos realizaram Olho por olho (1965). E é mesmo na rua que reconhecemos a maioria das cenas dos outros filmes dos anos 70 que se sucedem, quando um cinema marginal, porque feito sem recursos financeiros, porque feito na dissonância como uma série de padrões cinematográficos vigentes, era o cinema da invenção. Blá blá blá (1968) e a denúncia da ditadura, Bang bang (1970) e a expressão da revolta, o exorcismo pela desordem, que só pode se dar na tensão entre a implosão dramática e o rigor formal. 
Filmes já vistos, que agora se tocam por mero contato, por um jorro de escritura próprio à busca impossível pelo passado, portanto, também, jamais vistos. E junto a esses filmes inacabados e caseiros, em diversos suportes, o diário filmado entre 1960/98, At any time, Os últimos heróis de 1966, e A mulher do mafioso, de 1973.

$\mathrm{Na}$ primeira sequência, vemos do alto uma fumaça densa que sobe do centro de uma cidade, ambulâncias e caminhões de bombeiros, o movimento acelerado e o barulho da sirene se estende para as outras imagens de texturas e tempos muito diferentes, elas evocam, na relação com a trilha sonora, uma tensão constante, um sentimento de conflagração (conflito, revolta, guerra, morte) não só pela violência das cenas de alguns filmes, como Olho por olho, Bang bang e Blá blá blá, mas também pelos fragmentos de jornais e revistas, pelas imagens do exército armado, da aglomeração de pessoas. Conflagração essa sempre associada a uma coletividade, um país, uma guerra, uma ditadura, tempos difíceis. Lemos na manchete de um jornal: "O país chora a morte de JK", e ouvimos num off abafado pelo som da parada militar: "não há mais condições de manter a ordem nesse país": é Blá blá blá que atravessa o tempo e nos reencontra re-significado na memória de um cineasta que fala de si, que se autorretrata pelo outro, um em-si-para si que ao se constituir na superfície da tela assume sua exterioridade no e pelo cinema.

Em seu livro La mirada del retrato, Jean-Luc Nancy vai afirmar que autorretrato ${ }^{4}$ não é uma representação de um sujeito nem revela uma identidade, mas expõe um sujeito já exposto, uma vez que "o sujeito do retrato é o sujeito que o retrato mesmo é", pois é através do retrato que ele nasce tendo a superfície da tela como interface de um ser aí. "[...] é preciso [...] afirmar que a exterioridade não é somente um momento, mas também a substancia, o suporte, e a superfície do sujeito mesmo, sem prejuízo de suspender deste modo o retorno dialético ao si, ou de fazer desse retorno o que jamais um pensamento do sujeito sonhou fazer, mesmo que tudo o conduzisse a isso: a relação do retrato com seu espectador" (NANCY, 2006, p. 31).

Numa cadência de ritmos, que vai do grave ao melódico, outras imagens vêm arrefecer essa espreita por uma morte sempre coletiva, são filmes caseiros, intimistas, onde Tonacci se expõe, se filma, na maioria das vezes filmando, mas sem nunca assumir sua presença em demasia, como na cena em que $o$ vemos pelo reflexo do vidro sobreposto ao rapaz (talvez seu irmão) que toca um samba no cavaquinho, e às ainda pinturas de casa, algumas feitas pelo próprio cineasta.

Na terceira parte, que intitulamos de $O$ Pai, novamente o tom grave: sons que se assemelham a tiros de metralhadora e helicópteros evocam uma outra guerra. Novamente, a lupa aparece agora deslizando numa foto amarelada antiga como que procurando alguém entre um grupo de soldados combatentes, em outra foto um homem sorrindo veste um uniforme semelhante ao pai militar do menino explorador de Paixões. Esguio e alto, ele lembra Tonacci, a foto se funde com a de uma mulher sorrindo cujos

\footnotetext{
${ }^{4}$ Para Jean-Luc Nancy, todo retrato é um autorretrato e vice-versa. (NANCY, 2006, p. 34).
} 
traços também lembram os do cineasta, após uma sucessão de retratos de um e de outro ao som de uma música italiana, a foto de casamento. Não há dúvida de que são os pais de Tonacci, que se casaram em 1943, em Roma, durante a Segunda Grande Guerra. É o cineasta que olha pela lupa a foto de casamento, é pelo olhar do filho, o olhar que amplia, que a vemos: o homem, o pai, um recém repatriado fugido de um trem de prisioneiros italianos da Albania, "ela escaladora de montanhas e enfermeira voluntária nos hospitais romanos, o regime fascista em seus estertores." (TONACCI, 2012, p. 112). Ali, como ele mesmo lembra, Tonacci ainda é uma "total ausência" (2012, p. 112), só aparecerá depois, um menino loiro junto aos pais.

Entre essa sequência de fotos do arquivo de família surge um filme caseiro muito antigo, uma menina sorri e entra num carro que sai, da janela ela acena para aquele que fica com a câmera (talvez Tonacci), lembramos imediatamente das várias sequências de carros, traço inconteste dos filmes do cineasta, e principalmente desse movimento do carro que se vai com a câmera e abandona o corpo, o acontecimento, que se torna pequenino ao fundo do quadro. Nesse filme, é o carro que vai e a câmera que fíca só, pra trás. Não importa se ali estava o desejo do cineasta em seguir com o carro, ou se ali está a origem de um cinema por vir, mas sim a evocação de um presença ausente não só àquela própria da imagem, mas outra que se dobra sobre si mesmo: a presença de todos os filmes já vistos de Tonacci, que ao mesmo tempo em que estão ali, encapsulados nessa imagem-memória, dali se ausentam. Se uma ausência reside na impossibilidade do filme conter todos os filmes, ao modo de um Aleph borgiano cinematográfico ou de um cinema de Babel, a presença resiste na possibilidade do cinema de juntar temporalidades, de plissar o tempo. A velha imagem de família, em sua natureza de imagem-retrato $^{5}$, de vestígio, atualiza o passado na materialidade da película, nos movimentos que se processam no presente da assistência ao filme, porém, novamente, ao produzir esse presente, ela não cessa de evocar um ausente, não só passado que se foi, mas o gesto futuro de um cinema que ainda viria a acontecer, que por sua vez resta ali em potência.

Enquanto ainda vemos a lupa aumentar uma foto bem antiga da mãe no sofá com o cineasta menino, ouvimos a voz de Tonacci, algumas sobreimpressões e o vemos novamente trajando o mesmo uniforme do pai, junto ao filho que lê uma história: "precisamos ver se há mesmo uma causa para o medo". Em seguida, o cineasta pergunta a Joel, ator que faz o personagem com a lupa em Paixões, se para interpretar o militar, pai do garoto, ele ficaria melhor com ou sem o gorro. O fusca vermelho está encostado próximo à casa, quando Tonacci pede ao filho, Daniel, para contar uma história para a câmera, vemos então a imagem do menino caçador de tesouros de costas no alto de uma montanha de braços erguidos para o pôr do sol. É Tonacci (2012, p. 112) quem nos diz que essa tomada se deu pelo afetuoso desejo paterno para a vida do filho, é um gesto de vitória por um dia bem vivido. O cineasta conta que ela se confunde com uma

\footnotetext{
${ }^{5}$ Pensando o filme de família como um retrato de família, podemos seguir com Jean-Luc Nancy e pensar que no retrato: "eu não me assemelho senão a um rosto sempre ausente para mim e fora de mim, não como um reflexo, mas como um retrato a minha frente e sempre a frente de mim. [...] Não se assemelha a um original, mas se assemelha a ideia de semelhança a um original, ou melhor, o mesmo é o original do assemelhar-se a si de um sujeito geral, e também cada vez mais um sujeito singular... A cada retrato de mim mesmo se identificará outra semelhança". (NANCY, 2006, p. 48).
} 
reminiscência de infância, dele mesmo se sentindo vitorioso no alto da montanha e, diz ainda, que na lida com os arquivos para o filme encontrou a foto em preto e branco, em que como Dan, ele está de braços levantados, porém de frente pra câmera e de costas para os altos contrafortes dos montes Dolomiti: "uma sintonia imaginável, um encontro de memórias na imagem presente, imagens dando realidade aos sentimentos e intuições de filmar" (TONACCI, 2012, p. 113). Eis o gesto do filho que encontra o pai, que encontra o seu pai, que encontra o cineasta, o filme que ao ser feito faz nascer o já visto, e também o jamais visto, que só existe e só se pode descobrir no novo, no ato mesmo de rememorar.

O gesto autobiográfico, no qual o cineasta se inscreve ao se inscrever, é descentrado e nada totalitário, no sentido de não pretender preencher completamente a memória por uma ordem de eventos cronológicos que estabilize o passado numa história linear. A autobiografia é quase indireta, e transversal, na medida em que a memória do homem Tonacci se confunde com a do cinema brasileiro, e se faz a partir sempre do outro, do pai, do filho, da matéria fílmica, das parcerias, das imagens como outras. Tonacci responde a esse dever de memória do mundo atual ao temor que o passado seja solapado pelo imediatismo do presente, num gesto oposto ao historicista. Trata-se de um devir memória que é também devir filme, de um cinema no qual as imagens sobrevivem, sem se estagnarem, sem se referirem a uma realidade específica que precisa ser conservada. Um devir cinema que tem ele mesmo o mecanismo da memória, sua matéria porosa, onírica e lúdica, onde espaço, tempo, personagens permutam seus lugares, se fundem, onde os lugares da memória se transformam em objetos, imagens, lampejos de um tempo, e se intercambiam, figurando a cada cena e cada retomada a diferença entre passado e presente, no encontro mesmo entre ambos.

Diferente do dever de memória - que para preservá-la a pensa como inteira - o devir memória sabe que ela já é ausência, esquecimento, por isso aposta no presente, no processo de rememoração como um ato de sempre tornar-se. "O importante para o autor que rememora não e o que ele viveu, mas o tecido de sua rememoração, o trabalho de Penélope da reminiscência" (BENJAMIN, 1994, p. 37). É nesse trabalho de Penélope jamais acabado que o cineasta, historiador, recria o passado de uma vida não como ela foi, mas como será no filme, para e pelo filme, e para aquele que virá, o terceiro, o espectador. Esse cineasta é Tonacci, o menino explorador de objetos perdidos, relíquias passadas, como a enorme chave que o filho encontra, ou as esculturas gigantescas que ele adentra a fim de defrontar seus mistérios; o menino escavador de arquivos, e de um cinema brasileiro já na época inventivo. Eis que o inventor de Bang bang volta a inventar no ato de escavar e compor uma tessitura onde, como diria Benjamin, a recordação é a trama, mas o esquecimento é a urdidura. Mais que isso, o acontecimento vivido é finito, ao passo que o lembrado é sem limites. Como em Proust, trata-se da possibilidade e da potência de lembrar uma experiência nunca vivida, o inteiramente novo. Já visto é o passado que, no trabalho de memória, se descobre jamais visto. É também o trabalho do cinema que será sempre já visto e jamais visto. 
BENJAMIN, W. A imagem de Proust. In: Magia, técnica, arte e política. Obras escolhidas. São Paulo: Brasiliense, 1994.

CASTEllo BRANCO, Lucia. A traição de Penélope: uma leitura da escrita feminina na memória. Tese de doutorado. UFMG-FALE, 1990.

HARTOG, François. Regimes de Historicidade. Presentismo e Experiências do Tempo. Belo Horizonte: Editora Autêntica, 2013.

NORA, Pierre. Entre memória e história: a problemática dos lugares. Projeto História: Revista do Programa de Estudos Pós-Graduados em História e do Departamento de História da PUC-SP. São Paulo, 1981.

MONDZAIN. Marie José. Nada tudo qualquer coisa ou a arte das imagens como poder de transformação. In: SILVA, Rodrigo; NAZARÉ, Leonor (org). A república por vir. Arte, Política e Pensamento para o século XXI. Lisboa: Fundação Calouste Gulbenkian, 2011.

MOURÃO, P. Do arquivo ao filme: sobre Já visto jamais visto. Dossiê Tonacci. Revista Devires: Cinema e Humanidades. FAFICH-UFMG, v.9, n.2, jul/dez. 2012.

TONACCI, A. Fotogramas comentados. Dossiê Tonacci. Revista Devires: Cinema e Humanidades. FAFICH-UFMG, v.9, n.2, jul/dez. 2012.

Entrevista. In: BRASIL, GUIMARÃES e MESQUITA. Devir-Tonacci. Dossiê Tonacci. Revista Devires: Cinema e Humanidades. FAFICH-UFMG, v.9, n.2, jul/dez. 2012.

\section{Recebido em 13/05/2015. Aprovado em 20/05/2015.}

Title: Já visto jamais visto: a film of films, or the becoming-memory

Abstract: This essay explores how Andrea Tonacci's self-writing in his film Seen not seen (Já visto jamais visto, 2013) extracts its potency from the work of inventing memory. I suggest that Tonacci is not so much a character in a personal narrative, but mainly the filmmaker himself who, by putting his act in perspective as he looks back to 40 years of work, to recollections that were kept and forgotten in thousands of film reels, inhabits a space between images and subjects, a space in which filmmaking modulates temporal relations and come upon a gappy, pervious, oneiric, and mnemonic dimension. It is precisely because memory is constructed in the very process of filmmaking, and not as an outer element that one needs to recover or preserve as some sort of subjective possession, that it is not shown as a biographic or historic duty, but instead as a becoming, a cinematic becoming.

Keywords: Tonacci. Self-wrinting. Memory. Seen not seen. 